\title{
5. Freiwilligendienste als eine Form des freiwilligen Engagements
}

\author{
Claudia Vogel \& Julia Simonson
}

\section{Kernaussagen}

Freiwilligendienste sind spezifische und regulierte Formen des freiwilligen Engagements. Sie zeichnen sich neben der zeitlichen Befristung des Dienstes insbesondere durch feste Einsatzzeiten aus, die mit dem Stundenumfang von Vollzeit- oder Teilzeitbeschäftigungsverhältnissen vergleichbar sind. Von der Wohnbevölkerung im Alter von 18 und mehr Jahren haben 3,7 Prozent in der Vergangenheit einen Freiwilligendienst übernommen oder üben derzeit einen solchen aus.

Die Jugendfreiwilligendienste sind am weitesten verbreitet. Die Mehrheit der Personen, die einen Freiwilligendienst ausübt oder ausgeübt hat, hat ein Freiwilliges Soziales Jahr oder ein Freiwilliges Ökologisches Jahr gewählt. Nur ein kleiner Personenkreis hat andere Freiwilligendienste etwa im Ausland oder den Bundesfreiwilligendienst (seit 2011) gewählt.

Frauen entscheiden sich häufiger für einen Freiwilligendienst als Männer. Ein Grund dafür ist, dass in der Bundesrepublik mit der Wehrpflicht für Männer bereits ein Pflichtdienst bestand, der als Militär- oder aber als ein Ersatzdienst wie der Zivildienst ausgeübt werden musste. Die Wehrpflicht ist jedoch seit 2011 ausgesetzt: Künftig ist von einer Annäherung der Anteile von Männer und Frauen in Freiwilligendiensten auszugehen.

Freiwilligendienste werden am häufigsten von jungen Erwachsenen ausgeübt. Von den 18- bis 29-Jährigen haben 9,2 Prozent einen Freiwilligendienst absolviert, bei den 30- bis 49-Jährigen sind es nur 3,8 Prozent. Obwohl bei den Personen im mittleren und höheren Alter dieser Anteil aufgrund neuer Formate ohne Altersbegrenzung wie dem Bundesfreiwilligendienst auch noch steigen kann, ist festzuhalten, dass die Freiwilligendienste insgesamt bislang bei den Jüngsten am weitesten verbreitet sind. Für diese Geburtskohorten ist das stetig ausgeweitete Angebot an Plätzen in Freiwilligendiensten am größten.

Personen mit hohem Bildungsabschluss engagieren sich häufiger im Rahmen eines Freiwilligendienstes als Personen mit einem mittleren oder einem niedrigen Abschluss. Am häufigsten sind Freiwilligendienste in der Gruppe der 18- bis 29-Jährigen mit hoher Bildung verbreitet. In dieser Gruppe hat jede beziehungsweise jeder Zehnte einen solchen Dienst ausgeübt.

Personen, die in der Vergangenheit einen Freiwilligendienst absolviert haben, engagieren sich heute zu größeren Anteilen freiwillig als Personen, die keinen Freiwilligendienst absolviert haben. Für die Gruppe der freiwillig engagierten Männer lässt sich zudem zeigen, dass ein in der Vergangenheit geleisteter Freiwilligendienst anteilig wichtiger als Anstoß für ihr aktuelles Engagement ist als ein in der Vergangenheit geleisteter Zivildienst. 


\subsection{Einleitung}

Freiwilligendienste sind eine institutionalisierte Form zivilgesellschaftlichen Handelns (siehe Kapitel 1). Wir betrachten sie im Freiwilligensurvey als spezifische, auf einen Zeitraum von meist einem Jahr begrenzte und höchst zeitintensive Form des freiwilligen Engagements. Freiwilligendienste unterscheiden sich damit von anderen, mehr oder minder regelmäßigen, kurzfristigen oder über Jahre hinweg ausgeübten freiwilligen Tätigkeiten. In diesem Kapitel fragen wir insbesondere nach der Verbreitung von in der Vergangenheit absolvierten und derzeitig ausgeübten Freiwilligendiensten in unterschiedlichen Bevölkerungsgruppen, nach Geschlecht, nach Alters- und nach Bildungsgruppen.

Freiwilligendienste haben in der Bundesrepublik Deutschland eine lange Tradition. Das Freiwillige Soziale Jahr (FSJ) wurde 1964 ins Leben gerufen (Gesetz zur Förderung eines freiwilligen sozialen Jahres) ${ }^{1}$ als ein Jahr, in dem sich junge Menschen dazu verpflichten, überwiegend praktische Hilfstätigkeiten in gemeinwohlorientierten Einrichtungen zu leisten und von den persönlichkeitsbildenden und qualifizierenden Aspekten des Dienstes zu profitieren. Hervorgegangen ist das FSJ aus dem Diakonischen Jahr, das 1954 begründet wurde (Bundesministerium für Familie, Senioren, Frauen und Jugend (BMFSFJ) 2014b). Zusätzlich wurde 1993 das Freiwillige Ökologische Jahr (FÖJ) geschaffen, um die Einsatzfelder auf Umwelt- und Naturschutz auszuweiten. Mit dem Bundesfreiwilligendienst (BFD) wurde 2011 schließlich ein Freiwilligendienst eingeführt, der ab Erfüllung der Vollzeitschulpflicht für alle Altersgruppen offen ist. Anders als bei den Jugendfreiwilligendiensten, die sich an Jugendliche und junge Erwachsene bis einschließlich 27 Jahren richten, gibt es beim Bundesfreiwilligendienst keine Höchstaltersgrenze (Bundesamt für Familie und zivilgesellschaftliche Aufgaben (BAFzA) 2016). Er wurde nach Aussetzung der

1 Seit 2008 Gesetz zur Förderung von Jugendfreiwilligendiensten (Jugendfreiwilligendienstegesetz, JFDG).
Wehrpflicht und des Zivildiensts eingerichtet und soll das lebenslange Lernen fördern (Bundesfreiwilligendienstgesetz $(B F d G) \$ 1)$. Darüber hinaus bestehen zahlreiche andere Freiwilligendienstformate, die deutsche Staatsbürgerinnen und -bürger im In- und Ausland absolvieren können, etwa lokale Freiwilligendienste, der Europäische Freiwilligendienst (EFD), der entwicklungspolitische Freiwilligendienst, weltwärts oder der internationale Freiwilligendienst des Auswärtigen Amtes ,kulturweit', um nur einige Beispiele zu nennen.

Freiwilligendienste zeichnen sich in der Regel neben der zeitlichen Befristung insbesondere durch ihren Teilzeit- beziehungsweise Vollzeitcharakter aus, da sie ganztätig ausgeübt werden und sozialversicherungsrechtlich einer Ausbildung gleichgestellt sind. Die Dienste werden überwiegend über einen Zeitraum von sechs bis zwölf Monaten geleistet, teils auf 18 oder 24 Monate verlängert und pädagogisch begleitet (Jugendfreiwilligendienstegesetz (JFDG) §2). Sie umfassen meist eine wöchentliche Arbeitszeit von 20 bis 40 Stunden und werden mit einem Taschengeld vergütet, das bei einer Vollzeitstelle gesetzlich auf derzeit maximal 363 Euro monatlich begrenzt ist. Den Einsatzstellen entstehen neben den Kosten für das Taschengeld weitere Kosten für die Sozialversicherungsbeiträge (z. B. Krankenversicherung und gesetzliche Rentenversicherung) und die pädagogische Begleitung, die teils durch Bundeszuschüsse erstattet werden. ${ }^{2}$

Neben der Arbeitszeit werden auch die Aufgaben und die Zielsetzung der Tätigkeit zwischen den Trägerorganisationen (meist große Verbände wie das Deutsche Rote Kreuz oder der Paritätische Wohlfahrtsverband) und den Teil-

2 Auch der Bundesfreiwilligendienst ist nicht als sozialversicherungspflichtiges Beschäftigungsverhältnis ausgestaltet, sondern wird bei den Sozialversicherungen einem Ausbildungsverhältnis gleichgestellt (Bundesamt für Familie und zivilgesellschaftliche Aufgaben (BAFzA) 2016). 
nehmerinnen und Teilnehmern vertraglich geregelt (Jakob 2011). Als Zugangskriterien werden neben ausreichenden Deutschkenntnissen die deutsche Staatsbürgerschaft beziehungsweise ein Aufenthaltstitel, der auch zur Erwerbstätigkeit in Deutschland berechtigt, zur Ausübung eines Freiwilligendienstes vorausgesetzt.

Freiwilligendienste werden als Lernorte für Bildung sowie für die Übernahme sozialer Verantwortung diskutiert (Jakob 2011). Bislang eher mit Blick auf die Jugendfreiwilligendienste -aber auch im Bundesfreiwilligendienst - wird auf den Charakter der Dienste als eine Orientierungsphase im Lebenslauf beziehungsweise als Ausbildungsphase verwiesen (Jakob 2004). In Bezug auf ältere Menschen wird mittlerweile sogar ein Recht auf Teilnahme an einem Freiwilligendienst gefordert. Jeder Person soll nach dem Übergang in den Ruhestand offenstehen, auch in dieser Lebensphase aktiv teilzuhaben und Neues lernen zu können (Künzel 2014). Andererseits wurde bei Einführung des Bundesfreiwilligendienstes insbesondere kritisiert, der Staat greife zu stark in die Zivilgesellschaft ein: „Mit dem Bundesfreiwilligendienst wird ein staatlich geregelter und organisierter Freiwilligendienst geschaffen, mit dem der Staat direkt auf die Zivilgesellschaft zugreift und versucht, sie in seinem Sinn zu steuern“ (Jakob 2013: 2; vgl. auch Backhaus-Maul, Nährlich \& Speth 2011). Die Verbesserung der gesetzlichen Rahmenbedingungen von Freiwilligendiensten kann aus engagementpolitischer Sicht jedoch durchaus erfolgsversprechend sein. Kurzfristig, weil sich Menschen im Freiwilligendienst mit einem hohen Zeitaufwand engagieren, und langfristig, wenn die Teilnahme an einem Freiwilligendienst sich als bedeutsam für das weitere freiwillige Engagement im Lebenslauf einer Person erweist. Die Erfahrungen und Erlebnisse in einem solchen Dienst können biografisch später weiteres Engagement anregen. In diesem Kapitel untersuchen wir, wie wichtig der Freiwilligendienst als Anstoß für Engagement im Vergleich zu anderen Anlässen ist (siehe Kapitel 15). Gleichzeitig nehmen Personen, die sich bereits früher freiwillig engagiert haben, mög- licherweise häufiger an einem Freiwilligendienst teil (Picot 2004). Ausschlaggebend können dabei sowohl positive Erfahrungen im Engagement als auch zugrundeliegende Werthaltungen sein (siehe Kapitel 18).

Laut Bundesministerium für Familie, Senioren, Frauen und Jugend engagieren sich laufend ca. 100.000 Freiwillige in FSJ, FÖJ und BFD (Bundesministerium für Familie, Senioren, Frauen und Jugend (BMFSFJ) 2014a). In der alten Bundesrepublik gab es deutlich weniger Plätze in den Jugendfreiwilligendiensten, die sich in den 1960er und 1970er Jahren erst etablieren mussten, sodass die Anteile von Personen, die einen Freiwilligendienst absolvieren konnten, bei den heute Älteren deutlich geringer ausgefallen sind als bei den Jüngeren. Auch aufgrund der rechtlichen Rahmenbedingungen unterscheiden sich die Möglichkeiten für die verschiedenen Geburtsjahrgänge gravierend, einen Freiwilligendienst ausgeübt zu haben. Bei der Einführung des FSJ im Jahr 1964 hatten die vor 1938 geborenen Jahrgänge bereits die Höchstaltersgrenze von 27 Jahren überschritten; sie konnten kein Freiwilliges Soziales Jahr absolvieren (bei der Befragung im Jahr 2014 hatten diese Personen bereits das Alter von 77 Jahren erreicht).

Wie attraktiv Freiwilligendienste heute sind, zeigt sich auch daran, dass es in den letzten Jahren sogar deutlich mehr Bewerberinnen und Bewerber als verfügbare Plätze gab (Jax 2006: 71). Bisher wurden Jugendfreiwilligendienste vergleichsweise häufiger von jungen Erwachsenen mit Abitur (Liebig 2009) sowie von Frauen ausgeübt (Lincke 2012). Letzteres war möglicherweise der Fall, weil für Frauen in Deutschland nie eine Wehrpflicht bestand. Bei Frauen gab es also keine Konkurrenzsituation zwischen dem Pflichtdienst und einem Freiwilligendienst (Jax 2006: 81ff.). In der Deutschen Demokratischen Republik existierten keine Freiwilligendienste. ${ }^{3}$

3 Forderungen etwa der evangelischen Gemeinden, Freiwilligendienste wie einen sozialen Friedensdienst zu etablieren, konnten in der DDR nicht realisiert werden (Steinbach 2011). 
Die Wehrpflicht für Männer wurde in der Bundesrepublik Deutschland nach der Gründung der Bundeswehr im Jahr 1955 und in der Deutschen Demokratischen Republik ab 1962 eingeführt (Steinbach 2011). Der zivile Ersatzdienst, später Zivildienst, wurde in der Bundesrepublik als sozialer Ersatzdienst für Kriegsdienstverweigerer bereits 1961 eingeführt und in den folgenden Jahrzehnten mehrfach neu geregelt. Er dauerte in der Regel einige Monate länger als der Militärdienst. Wie die Dauer der Ersatzdienste war die Dauer des Militärdienstes zu verschiedenen Zeitpunkten sehr unterschiedlich geregelt, zudem hat sich die Einberufungspraxis der Bundeswehr mehrfach verändert. Der Zivildienst wurde nach und nach als gesellschaftliche Alternative zum Wehrdienst akzeptiert. 1998 hatten erstmalig mehr Wehrpflichtige den Kriegsdienst verweigert und den Zivildienst geleistet als Wehrpflichtige zur Bundeswehr eingezogen wurden (Werkner 2011). Anders als in der BRD gab es in der DDR keinen zivilen Ersatzdienst, sondern lediglich die Möglichkeit, beim Militär den Dienst an der Waffe durch den Einsatz als unbewaffneter Soldat (als sogenannter Bausoldat) zu umgehen (Steinbach 2011). Zudem konnten sich Männer in der Bundesrepublik auch die langjährige Mitarbeit im Zivil- oder Katastrophenschutz etwa bei der Freiwilligen Feuerwehr oder dem Technischen Hilfswerk als Ersatzdienst anrechnen lassen. In der Regel wählten sie jedoch den kürzeren Zivildienst als Wehrersatzdienst. Ab 2002 konnte laut Zivildienstgesetz auch ein FSJ oder ein FÖJ als Zivildienst beziehungsweise Wehrersatzdienst anerkannt werden. Zwischen 2002 und 2011 konnte ein Jugendfreiwilligendienst somit den Zivildienst auch ersetzen. Aufgrund der Tatsache, dass Männer bis zur Aussetzung der Wehrpflicht 2011 einen Pflichtdienst leisten mussten, ist von einer Konkurrenzsituation auszugehen: Über Jahrzehnte wählten Männer in der Bundesrepublik in der Regel keinen zusätzlichen Dienst, wenn sie ihren Pflichtdienst geleistet hatten. Seit Aussetzung der Wehrpflicht 2011 können sich Frauen und Männer gleichermaßen um den freiwilligen Wehrdienst bei der Bundeswehr bewerben.
Ob sich nach dem Aussetzen der Wehrpflicht die relativ großen Unterschiede in den Frauen- und Männeranteilen in Freiwilligendiensten angleichen werden, bleibt abzuwarten. Einerseits könnte man annehmen, dass insgesamt etwa genauso viele Männer wie Frauen freiwillig über einen gewissen Zeitraum einen Dienst leisten. Andererseits könnte der Geschlechterunterschied fortbestehen, da die Freiwilligendienste vor allem Tätigkeitsfelder wie Gesundheit und Soziales abdecken, in denen sich empirisch bislang mehr Frauen als Männer engagieren (siehe Kapitel 3). Laut Bundesarbeitskreis FSJ (2016) sind typische Einsatzstellen von Freiwilligendienstleistenden zum Beispiel in Kinder- und Jugendhilfeeinrichtungen, in Einrichtungen für behinderte Menschen, in Altenpflegeeinrichtungen sowie in Einrichtungen der politischen Bildung und Interessenvertretung $\mathrm{zu}$ finden. Da jedoch insgesamt deutlich mehr Männer als Frauen freiwillig engagiert sind, ist dauerhaft auch von einer Angleichung der Anteile in den Freiwilligendiensten auszugehen. Wir untersuchen, wie sich die Geschlechterunterschiede aktuell darstellen und ob sie sich bisher fortgeschrieben oder bei den jüngeren Altersgruppen bereits angeglichen haben. Offen ist darüber hinaus, ob künftig mehr Personen im mittleren und höheren Lebensalter den Bundesfreiwilligendienst leisten, der in jeder Lebensphase ausgeübt werden kann. Wir untersuchen, ob die Altersgruppenunterschiede auf eine Altersöffnung der Freiwilligendienste verweisen.

Das Ziel des Kapitels ist, die Teilnahme verschiedener Bevölkerungsgruppen an unterschiedlichen Freiwilligendiensten $\mathrm{zu}$ beschreiben. Die Zahl der Personen, die pro Jahr einen Freiwilligendienst aufnehmen, ist allerdings $\mathrm{zu}$ gering, um in der realisierten Stichprobe des Freiwilligensurveys eine ausreichende große Fallzahl für detaillierte Analysen zu erreichen (lediglich 41 Teilnehmerinnen und Teilnehmer des Freiwilligensurveys 2014 üben derzeit einen Freiwilligendienst aus). Daher wird die Verbreitung der von den Befragten in ihrer Vergangenheit und der Gegenwart geleisteten Freiwilligendienste 
kombiniert untersucht. Anders als beim Anteil freiwillig Engagierter, der widerspiegelt, wer sich in den letzten zwölf Monaten engagiert hat, wird mit der kombinierten Betrachtung der Freiwilligendienste für Vergangenheit und Gegenwart also gefragt, wer über den gesamten bisherigen Lebenslauf betrachtet bereits einen Freiwilligendienst absolviert hat. Dies wird im Folgenden gesondert für den Bundesfreiwilligendienst und für die Jugendfreiwilligendienste - Freiwilliges Soziales Jahr und Freiwilliges Ökologisches Jahr - dargestellt. Wie das frühere Absolvieren eines Freiwilligendienstes mit gegenwärtigem Engagement zusammenhängt, zeigen wir anhand der Retrospektivangaben.

In diesem Kapitel gehen wir folgenden Forschungsfragen nach:

1. Wer hat in der Vergangenheit einen Freiwilligendienst übernommen beziehungsweise übt diesen derzeit aus (differenziert nach Geschlecht, Altersgruppen und Bildung)?

2. Engagieren sich Personen auch heute häufiger, die in der Vergangenheit einen Freiwilligendienst ausgeübt haben als Personen, die keinen Freiwilligendienst ausgeübt haben?

3. Betrachten Engagierte, die in der Vergangenheit einen Freiwilligendienst ausgeübt haben, diesen auch als Anstoß für ihr heutiges freiwilliges Engagement? Und betrachten freiwillig engagierte Männer, die einen Freiwilligendienst ausgeübt haben, diesen anteilig häufiger als Anstoß für ihr Engagement, als jene Männer, die einen Zivildienst ausgeübt haben, eben diesen Zivildienst als Anstoß betrachten?

Retrospektivinformation wurde folgendermaßen erhoben:

Haben Sie einmal einen Freiwilligendienst geleistet, zum Beispiel ein Freiwilliges Soziales Jahr oder den Bundesfreiwilligendienst?

Wenn dies bejaht wurde, war die Folgefrage:

Welchen Freiwilligendienst haben Sie geleistet: Bundesfreiwilligendienst; Freiwilliges Soziales Jahr; Freiwilliges Ökologisches Jahr; sonstiger Freiwilligendienst?

Die Information zum derzeitigen Ausüben eines Freiwilligendienstes wurde im Rahmen des aktuellen Erwerbsstatus erhoben:

Sind Sie derzeit erwerbstätig; arbeitslos gemeldet; Schüler/in, in Ausbildung, im Studium; im Mutterschutz/in Elternzeit; Hausfrau, Hausmann; 
Rentner/in oder Pensionär/in; im freiwilligen Wehrdienst; in einem Freiwilligendienst; in Umschulung oder Weiterbildung; aus sonstigen Gründen nicht erwerbstätig?

Wer einen Freiwilligendienst angegeben hat, wurde gefragt:

Um welchen Freiwilligendienst handelt es sich dabei: Bundesfreiwilligendienst; Freiwilliges Soziales Jahr; Freiwilliges Ökologisches Jahr; sonstiger Freiwilligendienst?

Befragte, die einen sonstigen Freiwilligendienst angaben, wurden zudem jeweils nach dem Namen dieses Dienstes gefragt. Von Befragten wurden zum Beispiel der Europäische Friedensdienst oder ein Freiwilliges Kulturelles Jahr genannt.

Freiwilliges Soziales Jahr und Freiwilliges Ökologisches Jahr werden im Folgenden jeweils gemeinsam als Jugendfreiwilligendienste betrachtet, inklusive der offenen Angaben aus der Sonstiges-Kategorie, wenn diese (wie zum Beispiel ein Freiwilliges Kulturelles Jahr) eindeutig den Jugendfreiwilligendiensten zugeordnet werden konnten. Ein Jugendfreiwilligendienst wird in der Regel nach Abschluss der Schule aufgenommen, er kann aber auch in einer Phase zwischen unterschiedlichen Schul- und Ausbildungsphasen liegen. Da ein hoher Anteil der 14bis 17-Jährigen noch zur Schule geht und noch keinen Dienst absolvieren konnte, wurden ausschließlich Personen im Alter von 18 und mehr Jahren befragt, ob sie in der Vergangenheit einmal einen Freiwilligendienst geleistet haben. Bei der Darstellung der Ergebnisse wird die jüngste Altersgruppe daher im Folgenden mit 18 bis 29 Jahren eingegrenzt. Auf eine Höchstaltersgrenze in der Darstellung der Ergebnisse verzichten wir. Obwohl Personen, die im Jahr 2014 bereits 78 Jahre oder älter sind, historisch keine Möglichkeit hatten, ein Freiwilliges Soziales Jahr zu absolvieren (weil sie bei der Einführung des FSJ bereits älter als 27 Jahre waren) besteht potenziell die Möglichkeit, auch in diesem höheren Lebensalter noch einen Bundesfreiwilligendienst auszuüben.
Für alle freiwillig Engagierten wird im Freiwilligensurvey erhoben, woher der Anstoß kam, sich $\mathrm{zu}$ engagieren. Die Angaben zum Freiwilligendienst als Anstoß wurden in diesem Zusammenhang folgendermaßen erhoben:

Woher kam für Sie damals der Anstoß, die Tätigkeit zu übernehmen? Ich lese Ihnen nun verschiedene Möglichkeiten vor. Sagen Sie mir bitte jeweils, ob die Aussage zutrifft oder nicht zutrifft. Der Anstoß kam von: leitenden Personen aus Ihrer Gruppe oder Organisation; Familienmitgliedern, Freunden oder Bekannten, die dort schon aktiv waren; einer Informations- und Kontaktstelle; Hinweisen aus den Medien oder dem Internet; Erfahrungen in der Familie; Ihrer Tätigkeit während des Zivildienstes; Ihrer Tätigkeit während des Freiwilligendienstes; Ihrer Schule, Hochschule oder Ihrer Ausbildung; Ihrem Arbeitgeber.

Die Information zum Freiwilligendienst wurde nur bei Personen erhoben, die in der Vergangenheit einen Freiwilligendienst absolviert hatten. Die Angabe zum Zivildienst wurde nur bei Männern erhoben, die in der Vergangenheit einen Zivildienst absolviert hatten:

Haben Sie Pflichtwehrdienst, freiwilligen Wehrdienst, Zivildienst oder einen anderen Ersatzdienst geleistet? Antwortkategorien waren: ja, Pflichtwehrdienst; ja, freiwilligen Wehrdienst; ja, Zivildienst; ja, einen anderen Ersatzdienst; nein, nichts davon.

Eine Differenzierung nach Ost- und Westdeutschland ist uns über das Bundesland möglich, in dem die Befragten zum Zeitpunkt der Befragung leben. Berlin wird hierbei zusammen mit den fünf neuen Ländern zu Ostdeutschland gezählt (siehe Kapitel 22). Obwohl es in der DDR keine Möglichkeit gab, den Zivildienst oder einen Freiwilligendienst auszuüben, leben heute in beiden Landesteilen Personen, die das in der Vergangenheit in der alten Bundesrepublik oder nach der Wiedervereinigung in der heutigen Bundesrepublik getan haben. 


\subsection{Jugendfreiwilligendienste, Bundesfreiwilligendienst und sonstige Freiwilligendienste}

In welcher Bevölkerungsgruppe hat welcher Anteil an Personen einen Freiwilligendienst übernommen, und wenn ja, welche Art von Freiwilligendienst? Um diese Fragen zu beantworten, betrachten wir die kombinierten Anteile von Personen, die einen Freiwilligendienst in der Vergangenheit abgeschlossen haben (Retrospektivbetrachtung) sowie von Personen, die derzeit einen solchen ausüben. Letztere machen allerdings nur einen kleinen Bruchteil der Gesamtanteile aus und sind daher nicht gesondert ausgewiesen.

\subsubsection{Freiwilligendienste insgesamt}

Die Mehrheit der Personen, die einen Freiwilligendienst ausgeübt hat oder ausübt, hat die typischen Formate des Jugendfreiwilligendienstes als Freiwilliges Soziales Jahr oder als Freiwilliges Ökologisches Jahr gewählt. Nur ein sehr kleiner Personenkreis hat andere Freiwilligendienste etwa im Ausland oder den Bundesfreiwilligendienst absolviert (Abbildung 5-1a).

Von der Wohnbevölkerung im Alter von 18 und mehr Jahren haben 3,7 Prozent derzeit oder in der Vergangenheit einen Freiwilligendienst übernommen (Abbildung 5-1a). Dabei zeigt sich ein Unterschied nach Geschlecht. Frauen (4,5 Prozent) engagieren sich etwas häufiger im Rahmen eines Freiwilligendienstes als Männer (3,0 Prozent). Dies erscheint plausibel, da für Männer lange Zeit die Wehrpflicht galt und sie einen Freiwilligendienst zusätzlich zu Wehr- oder Zivildienst hätten absolvieren müssen. Allerdings gab es zwischen 2002 und 2011 auch die Möglichkeit, sich einen Freiwilligendienst als Äquivalent zum Zivildienst anerkennen zu lassen. Aus den Daten des Freiwilligensurveys ist nicht ersichtlich, wie viele der Männer ihren Freiwilligendienst statt des klassischen Zivildiensts absolviert haben.

Während die Beteiligung in Freiwilligendiensten bei den älteren Altersgruppen historisch bedingt deutlich geringer war, da die modernen Jugendfreiwilligendienste in deren Jugendphase noch nicht etabliert waren (lediglich 1,7 Prozent der 50- bis 64-Jährigen und 2,1 Prozent der 65-Jährigen und Älteren haben einen Freiwilligendienst absolviert), spielen Freiwilligendienste insbesondere in der Gruppe der jungen Erwachsenen heute eine nicht $\mathrm{zu}$ vernachlässigende Rolle: 9,2 Prozent der 18- bis 29-Jährigen haben einen Freiwilligendienst absolviert. Bei den 30- bis 49-Jährigen sind es lediglich 3,8 Prozent. Politisches Ziel ist es, dass künftig sogar mehr als jede beziehungsweise jeder Zehnte eines Jahrgangs einen Freiwilligendienst geleistet haben wird (Schwesig 2014). Bisher ist das lediglich bei den hochgebildeten 18- bis 29-Jährigen erreicht, nicht aber bei den Personen mit mittlerer oder niedriger Bildung (Tabelle 5-1a im Online-Anhang).

Obwohl auch der Anteil bei Personen im mittleren oder höheren Lebensalter aufgrund neuer Formate wie dem Bundesfreiwilligendienst noch steigen kann, ist festzuhalten, dass die Freiwilligendienste insgesamt bei der jüngsten Altersgruppe mit Abstand am weitesten verbreitet sind. Zudem ist davon auszugehen, dass der Anteil von jüngeren Personen, die einen Freiwilligendienst ausüben werden, künftig weiter ansteigt. Nach Aussetzen der Wehrpflicht wird ein Teil der Männer, die keinen Freiwilligendienst ausgeübt hätten, vermutlich künftig einen solchen übernehmen. Zudem haben Personen mit hohem Bildungsabschluss häufiger einen Freiwilligendienst ausgeübt (4,4 Prozent) als Personen mit einem mittleren (3,7 Prozent) oder einem niedrigen Schulabschluss (2,5 Prozent; Abbildung 5-1b).

Obwohl die Möglichkeit, einen Freiwilligendienst zu leisten bis zur Wiedervereinigung nur in der Bundesrepublik bestand, unterscheiden sich Ost- und Westdeutschland hinsichtlich der Anteile derer, die einen Freiwilligendienst 
absolviert haben oder absolvieren, insgesamt nur wenig. Von den heute in den neuen Bundesländern lebenden Menschen haben 3,3 Prozent einen Freiwilligendienst absolviert oder tun dies gegenwärtig, in den alten Bundesländern sind es 3,9 Prozent (Abbildung 5-1c). In der jüngsten Altersgruppe der 18- bis 29-Jährigen unterscheiden sich die Anteile der Freiwilligendienstleistenden nicht signifikant zwischen neuen (9,6 Prozent) und alten Bundesländern (9,1 Prozent; Tabelle 5-1d im Online-Anhang). Personen dieser Altersgruppe wurden in den Jahren 1985 bis 1996 geboren und haben ihren Freiwilligendienst dementsprechend nach der Wiedervereinigung absolviert. Bei den 30- bis 49-Jährigen lässt sich ebenfalls kein Unterschied feststellen (jeweils 3,8 Prozent). Personen dieser Altersgruppe wurden zwischen 1965 und 1984 geboren und dürften ihren Freiwilligendienst ebenfalls ganz überwiegend nach der Wiedervereinigung absolviert haben. Bei den älteren Altersgruppen sind die Quoten in beiden Landesteilen geringer, wobei jeweils mehr Personen in den alten Bundeslän- dern (50 bis 64 Jahre: 1,9 Prozent; 65 Jahre und älter: 2,3 Prozent) als in den neuen (50 bis 64 Jahre: 1,1 Prozent; 65 Jahre und älter: 1,2 Prozent) einen Freiwilligendienst absolviert haben. Die in Anbetracht der sich erst später eröffnenden Möglichkeiten für einen Freiwilligendienst immer noch vergleichsweise hohen Raten bei Älteren in den neuen Bundesländern lassen sich zum einen dadurch erklären, dass Personen auch in höherem Lebensalter noch einen Bundesfreiwilligendienst absolvieren können. Personen, die heute in den neuen Bundesländern leben, können zum anderen vor der Wiedervereinigung in der alten Bundesrepublik gelebt und dort einen Freiwilligendienst absolviert haben. Schließlich wird hier auch Berlin zu den neuen Bundesländern gezählt. In Westberlin gab es jedoch vor der Wiedervereinigung durchaus die Möglichkeit einen Freiwilligendienst zu absolvieren, zudem standen hier die Freiwilligendienste nicht in Konkurrenz zum Zivildienst, da Männer in Westberlin von der Wehrpflicht (und damit auch vom Zivildienst) ausgenommen waren.

Abbildung 5-1: Anteile von Personen, die einen Freiwilligendienst geleistet haben oder aktuell leisten, 2014, a) gesamt, nach Geschlecht und nach Alter, b) nach Bildung und c) nach Region

\section{a) gesamt, nach Geschlecht und nach Alter}

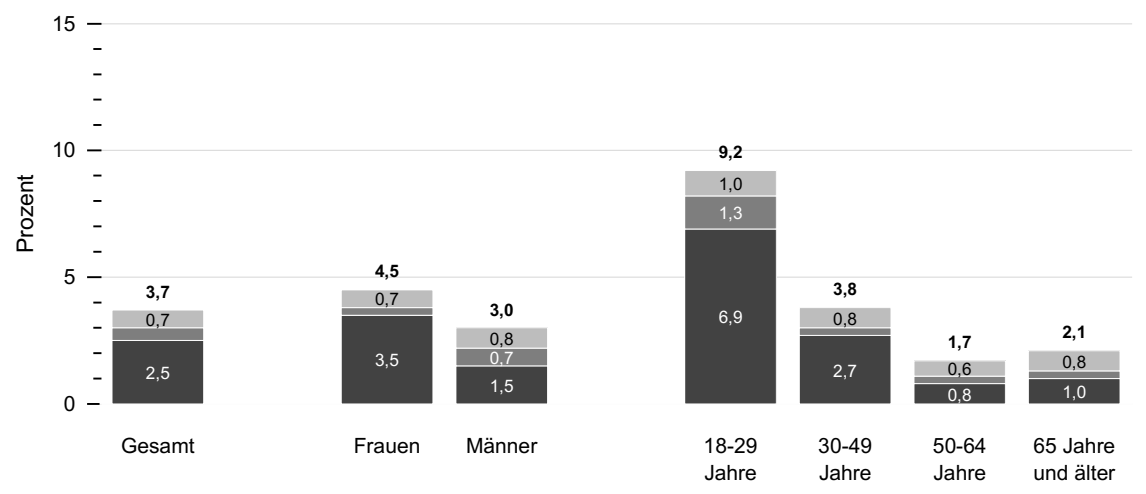




\section{b) nach Bildung}

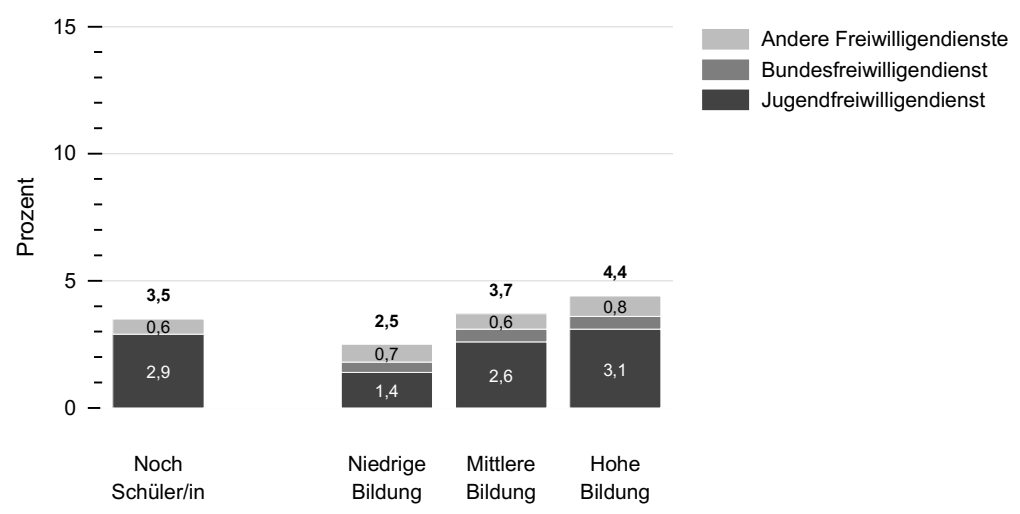

\section{c) nach Region}

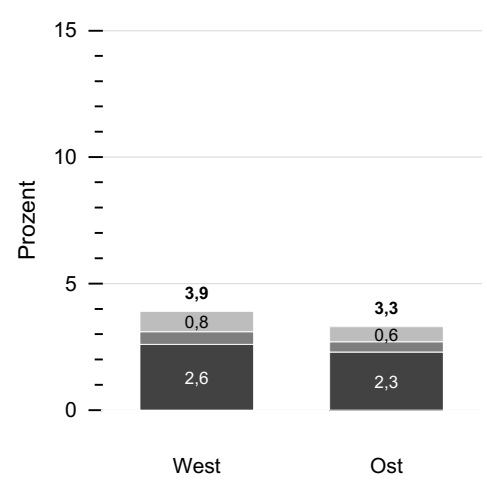

Quelle: FWS 2014, gewichtet, eigene Berechnungen (DZA). Basis: Alle Befragten ab 18 Jahre $(n=27.314)$. 
In allen Altersgruppen haben Frauen zu größeren Anteilen einen Freiwilligendienst übernommen als Männer (Abbildung 5-2a). Besonders ausgeprägt ist die Geschlechterdifferenz bei den 30- bis 49-Jährigen. Bei diesen haben 5,3 Prozent der Frauen einen Freiwilligendienst absolviert, aber nur 2,4 Prozent der Männer. Frauen haben sich darüber hinaus in allen Bildungsgruppen häufiger als Männer in einem Freiwilligendienst engagiert. Zudem sind die Bildungsunterschiede bei den Frauen besonders ausgeprägt, häufig werden Freiwilligendienste von Frauen mit hoher Bildung geleistet (Abbildung 5-2b). Am häufigsten sind Freiwilligendienste in der Gruppe der 18- bis 29-Jährigen mit hoher Bildung verbreitet, in dieser Gruppe hat jede beziehungsweise jeder Zehnte einen solchen Dienst ausgeübt (Abbildung 5-2c). Davon ausgehend, dass sich Personen nach ihrem Engagement im Rahmen eines Freiwilligendienstes auch künftig vergleichsweise häufiger etwa sozial oder politisch engagieren, könnte dieser hohe Anteil auch auf einen ansteigenden Trend im Anteil freiwillig Engagierter verweisen (siehe Kapitel 3). Allerdings sollte die überdurchschnittlich hohe Zahl junger Menschen in einem Freiwilligendienst nicht überinterpretiert werden, da ein Teil dieser Freiwilligendienste wahrscheinlich den Wegfall des Zivildienstes kompensiert. Einerseits werden Aufgaben in den Trägerorganisationen, die früher von Zivildienstleistenden übernommen wurden, heute durch Freiwilligendienstleistende etwa im Bundesfreiwilligendienst erfüllt; andererseits werden sich mehr Personen für einen Freiwilligendienst entscheiden, die dies früher aufgrund ihres bereits absolvierten Pflichtdienstes nicht getan hätten.

Abbildung 5-2: Anteile von Personen, die einen Freiwilligendienst geleistet haben oder aktuell leisten, 2014 a) nach Alter und Geschlecht, b) nach Bildung und Geschlecht, c) nach Alter und Bildung

a) nach Alter und Geschlecht

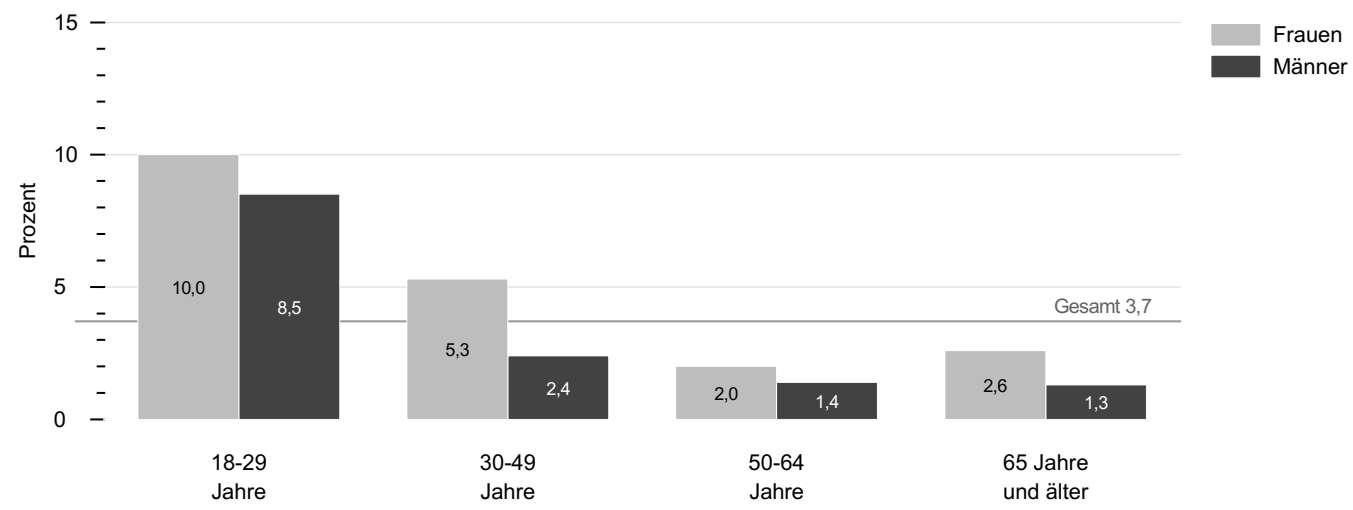




\section{b) nach Bildung und Geschlecht}

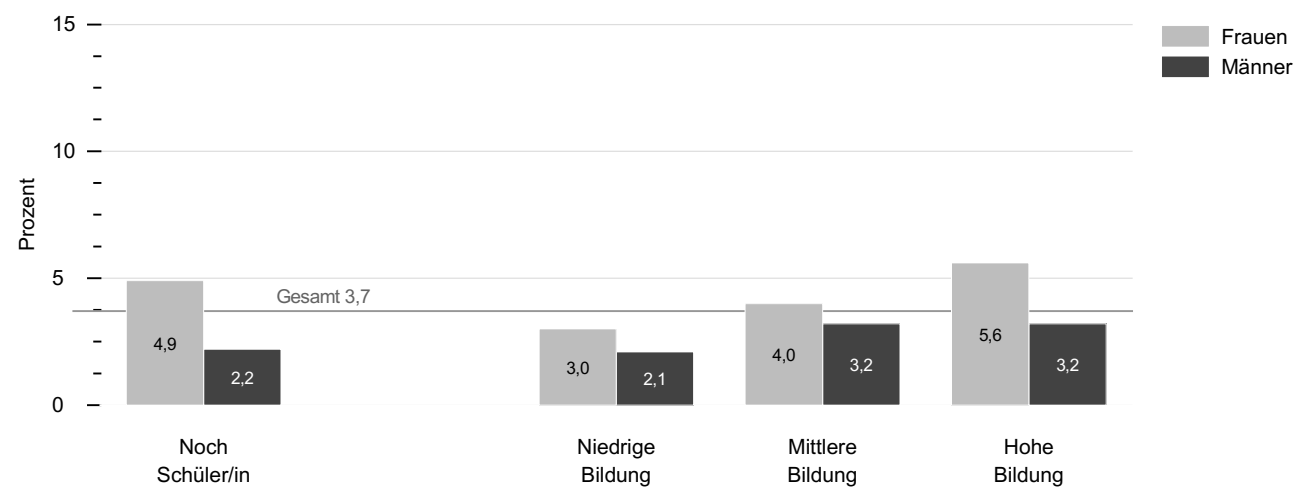

c) nach Alter und Bildung

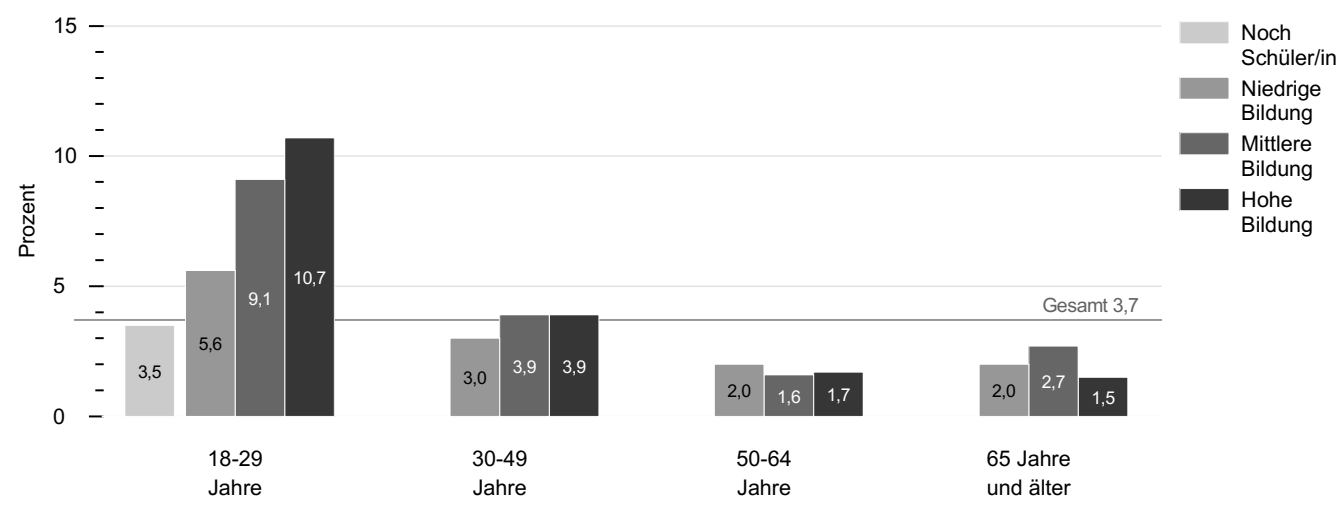

Quelle: FWS 2014, gewichtet, eigene Berechnungen (DZA). Basis: Alle Befragten ab 18 Jahre $(n=27.314)$.

\subsubsection{Jugendfreiwilligendienste}

Betrachten wir im Detail, welcher Anteil der Bevölkerung einen Jugendfreiwilligendienst übernommen hat - hierzu zählen sowohl das Freiwillige Soziale Jahr (FSJ) als auch das Freiwillige Ökologische Jahr (FÖJ) -, zeigt sich folgendes Bild: Von der erwachsenen Wohnbevölkerung (im Alter von 18 und mehr Jahren) hat lediglich eine kleine Gruppe von 2,5 Prozent in der Vergangenheit einen Jugendfreiwilligendienst absolviert oder absolviert derzeit einen solchen (Abbildung 5-1a). Diese Jugendfreiwilligendienste wurden beziehungsweise werden tendenziell häufiger von Frauen (3,5 Prozent) ausgeübt als von Männern (1,5 Prozent).

Mit 1,0 Prozent bei den Personen im Alter von 65 und mehr Jahren sowie mit 0,8 Prozent bei den Personen im Alter von 50 bis 64 Jahren ist die allgemein geringe Verbreitung von Freiwilligendiensten nochmals unterdurchschnittlich (Abbildung 5-1a). Anders sieht es bei den jüngeren Altersgruppen aus: 2,7 Prozent der 30- bis 49-Jährigen und sogar 6,9 Prozent der 18- bis 29-Jährigen haben einen Jugendfreiwilligendienst absolviert oder absolvierten ihn zum Zeitpunkt der Erhebung im Jahr 2014. Diese deutlichen Altersgruppenunterschiede lassen 
sich nicht allein darauf zurückführen, dass für Jugendfreiwilligendienste eine Höchstaltersgrenze von 27 Jahren gilt. Heute werden bei den verschiedenen Trägern deutlich mehr Freiwilligendienstplätze angeboten als früher.

Der bekannte Befund, dass Personen mit höherer Bildung häufiger einen Jugendfreiwilligendienst aufnehmen als Personen mit niedriger Bildung, wird durch die Ergebnisse des Freiwilligensurveys 2014 eindeutig repliziert: Von den Personen mit hoher Bildung haben 3,1 Prozent einen Jugendfreiwilligendienst absolviert, von den Personen mit niedriger Bildung lediglich 1,4 Prozent (Abbildung 5-1b). In der Gruppe derjenigen, die derzeit noch zur Schule gehen oder in Ausbildung sind, haben 2,9 Prozent bereits einen Jugendfreiwilligendienst geleistet. Ein Jugendfreiwilligendienst wird in der Regel nach der Schulzeit ausgeübt, manchmal wird ein Freiwilligendienst aber auch als Überbrückung zwischen einem ersten und einem weiterführenden Schulabschluss absolviert. Dass der Bildungsgradient sich bei den Jugendfreiwilligendiensten so deutlich zeigt, liegt sicherlich auch in der ökonomischen Existenzsicherung begründet (Anheier, Beller, Haß, Mildenberger \& Then 2012). Trotz des gewährten Taschengeldes ist eine gewisse finanzielle Freiheit Voraussetzung für ein solches Jahr, das heißt, die Finanzierung für Wohnung und Lebenshaltung muss gesichert sein. Aufgrund des geringen Taschengeldes eignen sich Freiwilligendienste auch nur bedingt, um eine Arbeitslosigkeitsphase zu überbrücken. Junge Erwachsene, die sich ihren Lebensunterhalt selbst verdienen müssen, werden eher sofort einer Erwerbsarbeit nachgehen wollen als solche, die ihren Lebensunterhalt etwa durch die finanzielle Unterstützung ihrer Eltern bestreiten können. Zum anderen starten Personen, die einen niedrigen Schulabschluss haben, in der Regel deutlich jünger in den Arbeitsmarkt, zum Beispiel schon mit 16 oder 17 Jahren. Die Hürde, eine bezahlte Arbeit aufzugeben, um einen Freiwilligendienst $\mathrm{zu}$ absolvieren, ist möglicherweise höher einzuschätzen als die Hürde, ein Jahr zwischen Abitur und Studium dafür aufzuwenden. Einzig für junge Menschen, die Arbeitslosengeld II beziehen, kann das Taschengeld im Freiwilligendienst das Einkommen verbessern.

\subsubsection{Bundesfreiwilligendienst}

Der Bundesfreiwilligendienst startete zum 1. Juli 2011. In dem vergleichsweise kurzen Zeitraum zwischen der Einführung des Bundesfreiwilligendienstes und der Befragung zur vierten Welle des Deutschen Freiwilligensurveys 2014 haben ca. 0,5 Prozent der erwachsenen Bevölkerung diesen Dienst ausgeübt (Abbildung 5-1a). Es gibt die Tendenz, dass Männer ihn häufiger antreten als Frauen. Das hängt möglicherweise damit zusammen, dass der Bundesfreiwilligendienst als Nachfolger des Zivildienstes betrachtet wird und sich Männer durch entsprechende Stellenangebote der Trägerorganisationen etwa für Fahrdienste direkt angesprochen fühlen. Interessierten Männern stehen ebenso wie interessierten Frauen neben den Jugendfreiwilligendiensten nun auch die Bundesfreiwilligenplätze mit ganz unterschiedlichen Tätigkeitsfeldern, nicht nur in der Pflege oder anderen sozialen Dienstleistungen, zur Verfügung. So können die Einsatzstellen Zusatzangebote aufrechterhalten, die ohne die Freiwilligen nicht zu leisten wären.

Es zeigt sich zudem, dass jüngere Personen im Alter bis 29 Jahre diese Art des Dienstes häufiger ausüben als ältere. Eine wesentliche Altersöffnung der Freiwilligendienste ist auf der Basis der Befunde zum Bundesfreiwilligendienst somit nicht zu beobachten. Eine weitere Differenzierung lässt sich allerdings auf Basis des Freiwilligensurveys zum jetzigen Zeitpunkt nicht vornehmen, weil die Verbreitung des Bundesfreiwilligendienstes bislang zu gering ist, um ihn in einer repräsentativen Bevölkerungsumfrage umfassend beobachten und beschreiben zu können. 


\subsection{Zusammenhang zwischen Freiwilligendiensten und freiwilligem Engagement}

In diesem Abschnitt untersuchen wir, ob sich Personen häufiger freiwillig engagieren, wenn sie in der Vergangenheit einen Freiwilligendienst ausgeübt haben und falls ja, ob dieser Effekt bei Frauen und Männern unterschiedlich ausgeprägt ist. Es ist anzunehmen, dass der Effekt bei Frauen stärker ist, weil sie in Deutschland nie einen Pflichtdienst (Wehrdienst oder Ersatzdienst) leisten mussten und die Entscheidung für einen freiwilligen Dienst das weitere Engagement im Lebenslauf stärker prägt. In der Bundesrepublik (mit Ausnahme Westberlins) waren von den Männern bis zum Jahr 2011 alle Jahrgänge ab der Geburtskohorte 1937 vom Pflichtdienst betroffen, ebenso wie die Wehrdienstleistenden in der DDR. Tatsächlich mussten allerdings in der BRD jüngere Kohorten seltener einen Wehr- oder Ersatzdienst leisten, da die Zahl der Ausmusterungen im Zeitverlauf deutlich zunahm. Ein zusätzlicher Freiwilligendienst hatte auf Männer, die bereits einen Pflichtdienst absolviert haben, möglicherweise weniger Einfluss als auf Frauen, die keinen Pflichtdienst absolvieren mussten. Zudem haben nur sehr wenige Männer beides geleistet, den Pflichtdienst und einen zusätzlichen Freiwilligendienst, der nicht als Ersatz für den Pflichtdienst angerechnet wurde.

\subsubsection{Freiwilligendienst in der Vergangenheit und heutiges freiwilliges Engagement}

Vergleichen wir den Anteil Engagierter in der Gruppe der Personen, die in der Vergangenheit einen Freiwilligendienst absolviert haben, mit dem Anteil Engagierter in der Gruppe der Personen, die nie einen solchen Dienst übernommen haben, zeigt sich, dass der Anteil bei der ersten Gruppe mit 50,0 Prozent deutlich höher ist als in der zweiten Gruppe (43,3 Prozent) (Abbildung 5-3).

Abbildung 5-3: Anteile freiwillig Engagierter bei Personen, die einen Freiwilligendienst absolviert haben und bei Personen, die keinen Freiwilligendienst absolviert haben, 2014

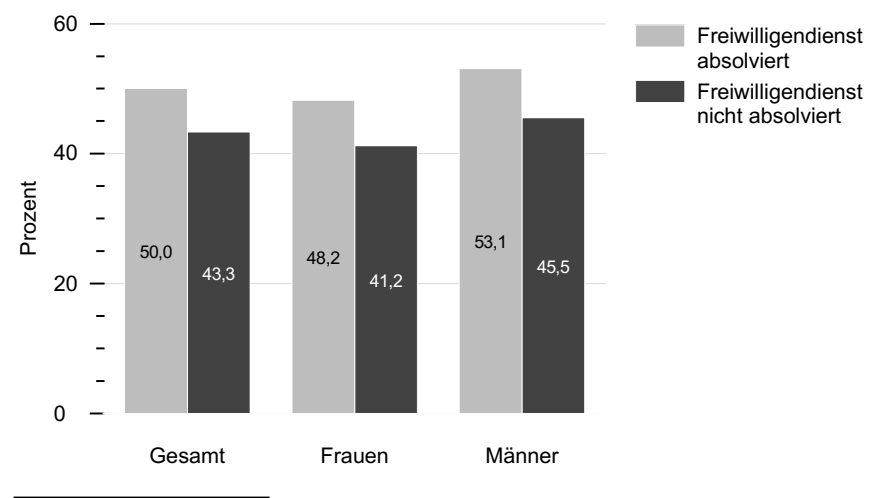

Quelle: FWS 2014, gewichtet, eigene Berechnungen (DZA). Basis: Alle Befragten ( $n=28.689$ ).

Personen, die einen Freiwilligendienst absolviert haben, engagieren sich auch später im Lebenslauf tatsächlich häufiger freiwillig. Dieser Zusammen- hang ist sowohl bei Frauen (48,2 Prozent zu 41,2 Prozent) als auch bei Männern (53,1 Prozent versus 45,5 Prozent) zu beobachten. Ein Vergleich 
der Prozentsatzdifferenz zeigt: Der Unterschied ist bei Männern in absoluten Prozentpunkten lediglich minimal stärker (7,6 Prozentpunkte Unterschied zu 7,0 Prozentpunkte Unterschied). Jedoch ist die Gruppe derjenigen, die Erfahrung mit einem Freiwilligendienst hat, bei den Männern insgesamt vergleichsweise gering. Das heißt, der Effekt ist bei Frauen nicht stärker, aber insgesamt haben viel mehr Frauen als Männer Erfahrungen im Freiwilligendienst gesammelt, die späteres Engagement begünstigen können.

Bei Personen, die in den neuen Bundesländern leben, sind die Unterschiede in den Anteilen Engagierter zwischen denjenigen, die einen Freiwilligendienst absolviert haben und die dies nicht gemacht haben (52,2 Prozent zu 38,1 Prozent), zudem größer als in den alten Bundesländern (49,6 Prozent zu 44,6 Prozent); dies gilt sowohl für Männer als auch für Frauen (ohne Abbildung; Tabelle 5-2 im Online-Anhang). Der Engagement begünstigende Effekt der Freiwilligendienste könnte also in den neuen Bundesländern stärker ausgeprägt sein, möglicherweise spielen hier aber auch Selektionsprozesse eine Rolle. Dies ist der Fall, wenn sich beispielsweise Personen, die einen Freiwilligendienst wählen, in den neuen Bundesländern stärker als in den alten Bundesländern in ihren Wertvorstellungen von denen unterscheiden, die keinen Freiwilligendienst ausüben.

\subsubsection{Freiwilligendienst und Zivildienst als Anstöße für heutiges freiwilliges Engagement}

Wie häufig nennen Personen, die einen Freiwilligendienst ausgeübt haben, diesen als Anstoß für ihr heutiges freiwilliges Engagement? Zunächst muss daran erinnert werden, dass lediglich eine Minderheit der Bevölkerung im Alter von 18 und mehr Jahren Erfahrungen in einem Freiwilligendienst gesammelt hat. Auch von allen Engagierten haben lediglich rund vier Prozent in der Vergangenheit einen Freiwilligendienst absolviert. Für diese war die Erfahrung jedoch häufig prägend, wie diese Ergebnisse verdeutlichen: Über alle Altersgruppen hinweg nennen knapp ein Viertel (23,3 Prozent) derjenigen, die engagiert sind und in der Vergangenheit einen Freiwilligendienst geleistet haben, diesen als Anstoß für ihr Engagement (Abbildung 5-4). Frauen und Männer nennen diesen Anstoß zu gleichen Anteilen (Frauen 23,3 Prozent; Männer 23,4 Prozent). Betrachten wir jedoch ausschließlich die Altersgruppe der 18- bis 29-Jährigen, zeigt sich, dass für 32,7 Prozent der engagierten Frauen und für 24,6 Prozent der engagierten Männer ihr früherer Freiwilligendienst Anstoß für heutiges Engagement war (Tabelle 5-3a im Online-Anhang).

Man könnte nun von einem Potenzial der Freiwilligendienste sprechen, soziale Ungleichheit im Engagement zu reduzieren, wenn besonders viele Engagierte mit geringer Bildung dies als Anstoß nennen. Tatsächlich nennen von den Engagierten mit niedriger Bildung 32,2 Prozent ihren früheren Freiwilligendienst als Anstoß für ihr derzeitiges Engagement, von den Engagierten mit mittlerer Bildung 24,0 Prozent und von den Engagierten mit hoher Bildung lediglich 21,3 Prozent (Tabelle 5-3b im Online-Anhang). Für niedriggebildete Personen ist der Freiwilligendienst offensichtlich häufiger ein Anstoß als für hochgebildete Personen. Soziale Ungleichheit im Engagement, über den gesamten Lebenslauf betrachtet, könnte also möglicherweise verringert werden, wenn mehr Personen mit niedriger und mittlerer Bildung als bislang für einen Freiwilligendienst geworben werden könnten.

Wie wichtig ist der Freiwilligendienst als Impulsgeber für Engagement im Vergleich zu anderen Gründen, die von ehemaligen Freiwilligendienstleistenden genannt werden? Als Anstoß für Engagement nimmt der Freiwilligendienst eine mittlere Position ein (Abbildung 5-4; zu den Anstößen für Engagement bei allen Engagierten siehe Kapitel 15). Wesentlich häufiger werden Erfahrungen in der Familie oder die Ansprache durch Familienmitglieder oder Freunde und Bekannte genannt, wesentlich seltener die Informations- und Kontaktstellen oder Medien 
und Internet, und Institutionen wie Schule und Hochschule beziehungsweise der Betrieb oder der Arbeitgeber. Der Freiwilligendienst ist insofern für viele derjenigen, die einen solchen absolviert haben, eine prägende Erfahrung, wird in seiner Bedeutung als Anstoß für freiwilliges Engagement aber von anderen Impulsgebern wie Mitgliedern der Familie oder des Freundes- und Bekanntenkreises übertroffen.

\section{Abbildung 5-4: Anstöße für Engagement bei Personen, die einen Freiwilligendienst absolviert haben, 2014}

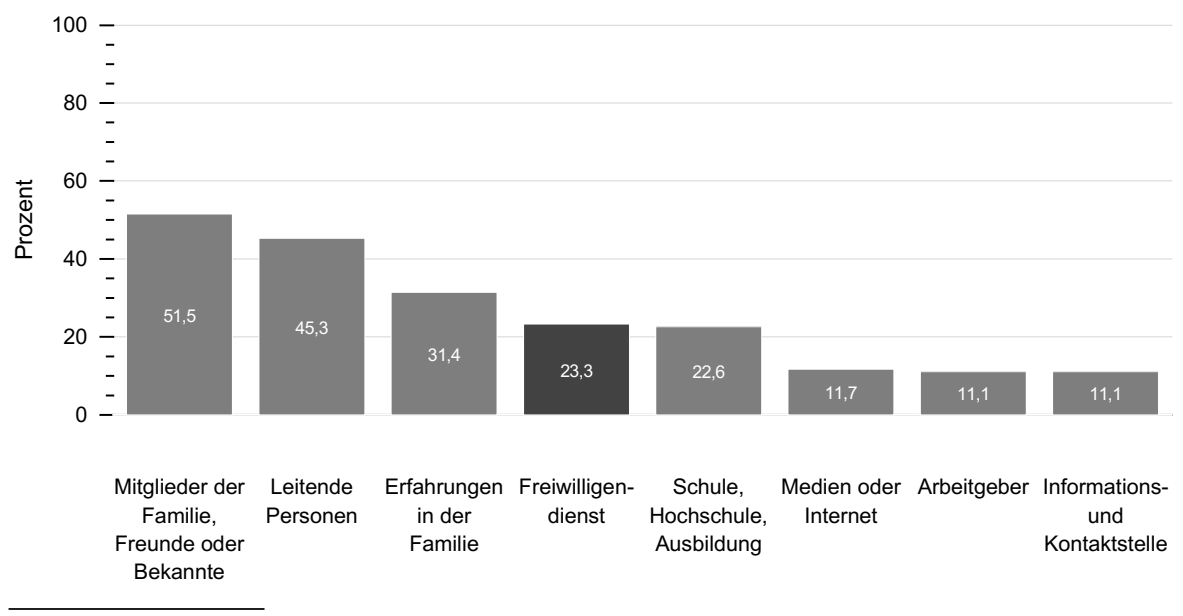

Quelle: FWS 2014, gewichtet, eigene Berechnungen (DZA). Mehrfachnennungen. Basis: Alle Personen ab 18 Jahren, die einen Freiwilligendienst absolviert haben und freiwillig engagiert sind $(n=498)$.

\section{Abbildung 5-5: Freiwilligendienst und Zivildienst als Anstoß im Vergleich (nur Männer), 2014}

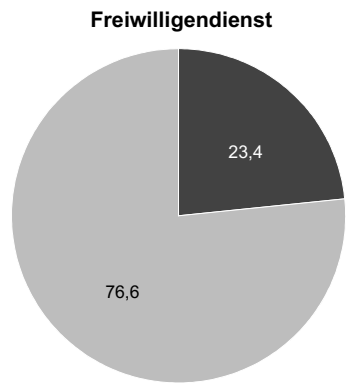

Engagierte, die Freiwilligendienst als Anstoß für Engagement nennen

Engagierte, die Freiwilligendienst absolvierten, diesen aber nicht als Anstoß für ihr Engagement bezeichnen

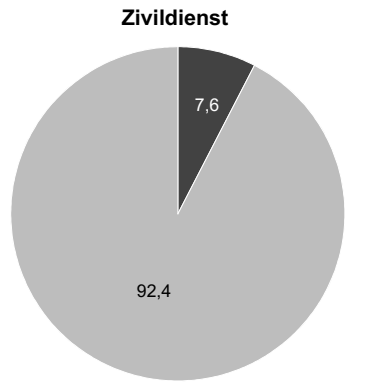

Engagierte, die Zivildienst als Anstoß für Engagement nennen

Engagierte, die Zivildienst absolvierten, diesen aber nicht als Anstoß für ihr Engagement nennen

Quelle: FWS 2014, gewichtet, eigene Berechnungen (DZA). Basis: Alle Männer, die einen Freiwilligendienst absolviert haben und freiwillig engagiert sind $(n=176)$ beziehungsweise alle Männer, die einen Zivildienst absolviert haben und freiwillig engagiert sind $(n=563)$. 
Ausschließlich für die Gruppe der Männer können wir zudem vergleichen, ob ein Zivildienst oder ein Freiwilligendienst häufiger als Anstoß für das heutige Engagement genannt werden. Lediglich 7,6 Prozent der Männer, die in der Vergangenheit einen Zivildienst absolviert haben, nennen diesen als Anstoß. Im Vergleich

\subsection{Fazit}

Freiwilligendienste sind eine spezifische und gesetzlich regulierte Form des freiwilligen Engagements, die sich neben der zeitlichen Befristung des Dienstes insbesondere durch feste Einsatzzeiten auszeichnen und im Stundenumfang mit Vollzeit- oder Teilzeitbeschäftigungsverhältnissen vergleichbar sind. Freiwilligendienste sind somit eine sehr zeitintensive Form des Engagements, in der die Freiwilligen praktisch ein ganzes Jahr ihres Lebens spenden, um anderen zu helfen. Die Mehrheit der Personen, die einen Freiwilligendienst ausübt oder ausgeübt hat, hat die typischen Formate des Jugendfreiwilligendienstes, also ein Freiwilliges Soziales Jahr oder ein Freiwilliges Ökologisches Jahr gewählt, ein deutlich kleinerer Personenkreis hat den noch vergleichsweise neuen Bundesfreiwilligendienst oder einen anderen Freiwilligendienst absolviert.

Frauen üben etwas häufiger einen Freiwilligendienst aus als Männer. Künftig ist allerdings von einer Angleichung auszugehen: Da die Wehrpflicht ausgesetzt und somit auch kein Ersatzdienst mehr für Männer notwendig ist, werden diese voraussichtlich häufiger einen Freiwilligendienst wählen als in der Vergangenheit. Zudem hat sich die Übernahme eines sozialen Dienstes für Männer durch die breite gesellschaftliche Akzeptanz des Zivildienstes etabliert und macht auch einen freiwilligen Dienst in sozialen Tätigkeitsfeldern für Männer wahrscheinlicher. Freiwilligendienste spielen darüber hinaus bislang insbesondere in der Gruppe der jungen Erwachsenen eine bedeutende Rolle. Eine wesentliche Altersöffnung durch den Bundesfreiwilligendienst hat - in der Gesamtbetrachtung zu 23,4 Prozent beim Freiwilligendienst war der Zivildienst somit ein weniger wichtiger Anstoß für das freiwillige Engagement der Männer (Abbildung 5-5). Dies ist plausibel, da es sich beim Zivildienst eben nicht um einen freiwilligen selbstgewählten Dienst, sondern als Wehrersatzdienst auch um einen Pflichtdienst handelte.

der Freiwilligendienste auf Basis des Freiwilligensurveys - bislang noch nicht stattgefunden. Aus der bisher vergleichsweisen geringen Beteiligung von Personen im höheren Lebensalter schließen auch Haß und Beller (2015), dass die Altersöffnung der Freiwilligendienste beidseitig, das heißt sowohl von Seiten der Einsatzstellen als auch von Seiten der Interessierten, noch nicht abgeschlossen ist. Dementsprechend diskutieren Anheier, Beller, Haß, Mildenberger und Then (2012) auch bestehende Zugangsbarrieren für Ältere sowie für Personen in biografischen Umbruchssituationen und schlussfolgern, dass entsprechende Tätigkeitsprofile für Ältere erst geschaffen und Ältere über die Angebote breiter informiert werden müssten. Die Inklusionsbeauftragte der Bundesregierung weist zudem auf Zugangsbarrieren beim Bundesfreiwilligendienst für Menschen mit Behinderung hin, da diese für eine benötigte Assistenz wie technische Hilfsmittel oder Personal privat aufkommen müssen (in regulären Beschäftigungsverhältnissen werden die Kosten für technische Assistenz erstattet; Deutscher Bundestag 2015). Der Bundesfreiwilligendienst soll aber allen Menschen gleichermaßen offenstehen (Beauftragte der Bundesregierung für die Belange behinderter Menschen 2011).

Darüber hinaus ist der Bildungsgradient im freiwilligen Engagement allgemein stark. Dies gilt im besonderen Maße auch für die Freiwilligendienste: Sie werden deutlich häufiger von Personen mit hohem Schulbildungsabschluss ausgeübt als von Personen mit niedrigem Schulbildungsabschluss. Um soziale Ungleichheiten abzubauen, sollten sich Freiwilligendienste ver- 
stärkt ausdrücklich an Personen mit mittlerer und vor allem mit niedriger Bildung richten, und bestehende Zugangsbarrieren sollten abgebaut werden. Diese Schlussfolgerung ist auch vor dem Hintergrund $\mathrm{zu}$ sehen, dass Freiwilligendienste ein wichtiger Anstoß für weiteres Engagement sein können. Personen, die in der Vergangenheit einen Freiwilligendienst ausgeübt haben, engagieren sich heute auch häufiger freiwillig. In unserer Querschnittsbetrachtung können wir aber keine Ursache-Wirkung-Richtung identifizieren; die Erfahrungen in einem Freiwilligendienst können dazu beitragen, dass sich Personen auch im Anschluss freiwillig engagieren, genauso gut ist es möglich, dass sich Personen, die sich bereits freiwillig engagiert haben, dazu entscheiden, einen Freiwilligendienst zu übernehmen. Möglicherweise bedingen dieselben Faktoren freiwilliges Engagement in der Form des Freiwilligendienstes sowie in anderen Formen.

Trotz ihrer möglicherweise engagementfördernden Wirkung werden Freiwilligendienste in der Engagement- und der Sozialpolitikforschung auch kritisch diskutiert. Befürchtet wird etwa, dass die Konstruktion von Freiwilligendiensten, wie der Bundesfreiwilligendienst, eine Monetarisierung des bürgerschaftlichen Engagements befördert, weil diese Dienste mit einem Taschengeld vergütet werden (Jakob 2011; siehe Kapitel 14). Die Bundesagentur für Arbeit klassifiziert die Jugendfreiwilligendienste auch als sozialversicherungspflichtige Beschäftigungsverhältnisse, da die Trägerorganisationen Sozialversicherungsbeiträge für die Freiwilligendienstleistenden abführen müssen (Frank \& Grimm 2014). Von Gewerkschaftsseite wird kritisiert, dass es sich bei den Freiwilligendiensten um eine Form prekärer Beschäftigung handelt. Diese Kritik richtet sich meist gegen den Bundesfreiwilligendienst. Jugendfreiwilligendienste werden eher als Aus- oder Weiterbildung und weniger in Konkurrenz zu regulärer Beschäftigung gesehen. Notz (2012) weist insbesondere darauf hin, dass der Bundesfreiwilligendienst es Trägern erleichtert, den gesetzlichen Mindestlohn zu umgehen. Von Teilnehmerinnen und Teilnehmern am Bundesfreiwilligendienst wird dieser tatsächlich teils auch als Alternative zur Erwerbsarbeit gewählt, oder auch als sinnstiftende Aufgabe im Ruhestand (Beller \& Haß 2013).

Neben aller Kritik sollte allerdings auch berücksichtigt werden, dass staatliche Akteure wichtige Impulse geben können und durch neue Formate oder geeignete Förderinstrumente etwa die Ansprache spezifischer Bevölkerungsgruppen wie Personen mit geringer Bildung oder Älterer für einen Freiwilligendienst voranbringen können. Auch die Zielgruppe der Migrantinnen und Migranten sollte besonders angesprochen werden, um die Integration durch einen Freiwilligendienst $\mathrm{zu}$ erleichtern (Schmidle \& Slüter 2012). Als Beispiel für ein neu anzustoßendes Format sei hier das ,Freiwillige Soziale Jahr Digital' genannt, das die Bundesregierung im Rahmen der Digitalen Agenda entwickelt und für das erste Einsatzstellen im Rahmen eines Modellprojektes beworben werden (Bundesregierung 2016). Auch oder vor allem die Trägerorganisationen, bei denen die Auswahl der Freiwilligen tatsächlich stattfinden, sollten darauf achten, auch vermehrt Personen mit geringeren Bildungsressourcen oder Personen mit Migrationshintergrund eine Chance zu geben. Betrachtet man die heute bereits vergleichsweise hohen Teilnahmequoten der 18- bis 29-Jährigen, kann man schlussfolgern, dass Freiwilligendienste historisch bedeutsamer sind als je zuvor. Diese Art des freiwilligen Engagements wird durch den Ausbau und die Entwicklung weiterer Freiwilligendienstformate sicherlich noch zunehmen. Personen im Freiwilligendienst berichten überwiegend positive Aspekte, insbesondere die persönlichen Erfahrungen stehen hier im Vordergrund (Wersig 2015). Diese erscheinen auch als ausschlaggebend für die Ausübung weiteren Engagements im Lebenslauf. 


\section{Literatur}

Anheier, H. K., Beller, A., Haß, R., Mildenberger, G., \& Then, V. (2012). Ein Jahr Bundesfreiwilligendienst. Erste Erkenntnisse einer begleitenden Untersuchung. Heidelberg: Centrum für soziale Investitionen und Innovationen (CSI) \& Hertie School of Governance.

Backhaus-Maul, H., Nährlich, S., \& Speth, R. (2011). Der diskrete Charme des neuen Bundesfreiwilligendienstes. Aus Politik und Zeitgeschichte, 61(48), 46-53.

Beauftragte der Bundesregierung für die Belange behinderter Menschen (2011). Bundesbeauftragte: „Unterstützungsbedarf ist kein Hindernis für ein Freiwilligenengagement" - Einsatz von Menschen mit Behinderung im Bundesfreiwilligendienst wird begrüßt. Online: http://www.behindertenbeauftragte.de/SharedDocs/Pressemitteilungen/ DE/2011/PM46_Bundesfreiwilligendienst_cm.html (zuletzt abgerufen 5.2.2016).

Beller, A., \& Haß, R. (2013). Experiment Altersöffnung: Politische Ziele und nicht-intendierte Folgen - empirische Befunde aus der Pionierphase des Bundesfreiwilligendienstes. Voluntaris - Zeitschrift für Freiwilligendienste, 1(2), 51-72.

Bundesamt für Familie und zivilgesellschaftliche Aufgaben (BAFZA) (2016). Bundesfreiwilligendienst. Online: https:// www.bundesfreiwilligendienst.de/der-bundesfreiwilligendienst/oft-gestellte-fragen.html (zuletzt abgerufen 5.2.2016).

Bundesarbeitskreis FSJ (2016). Einsatzstelle. Online: http://pro-fsj.de/de/fsj-lexikon (zuletzt abgerufen 5.2.2016).

Bundesministerium für Familie, Senioren, Frauen und Jugend (BMFSFJ) (2014a). 50 Jahre Freiwilliges Soziales Jahr. Online: http://www.bmfsfj.de/BMFSFJ/Service/volltextsuche,did=206018.html (zuletzt abgerufen 5.2.2016).

Bundesministerium für Familie, Senioren, Frauen und Jugend (BMFSFJ) (2014b). 50 Jahre FSJ. Die Geschichte des FSJ. Online: http://www.50-jahre-fsj.de (zuletzt abgerufen 9.12.2014).

Bundesregierung (2016). Freiwilliges Soziales Jahr Digital. Ehrenamtlich am Computer. Online: http://www.bundesregierung.de/Content/DE/Artikel/2014/09/2014-09-18-fsj-digital.html (zuletzt abgerufen 5.2.2016).

Deutscher Bundestag (2015). Kurzprotokoll der 11. Sitzung des Unterausschusses ,Bürgerschaftliches Engagement' vom 18. März 2015. Online: https://www.bundestag.de/blob/369520/35e227a2691f30cfe66b30b6e09fac89/11_sitzung_ kurzprotokoll_oeff-data.pdf (zuletzt abgerufen 5.2.2016).

Frank, T., \& Grimm, C. (2014). Beschäftigungsstatistik Revision 2014. Nürnberg: Bundesagentur für Arbeit.

Haß, R., \& Beller, A. (2015). Der Bundesfreiwilligendienst: Ein Erfolgsmodell für alle? Aus Politik und Zeitgeschichte, 65(14/15), 22-28.

Jakob, G. (2013). Freiwilligendienste zwischen Staat und Zivilgesellschaft (betrifft: Bürgergesellschaft 40). Berlin: Friedrich-Ebert-Stiftung.

Jakob, G. (2011). Freiwilligendienste. In: B. Hartnuß \& T. Olk (Hrsg.) Handbuch Bürgerschaftliches Engagement (S. 185201). Weinheim: Beltz Juventa.

Jakob, G. (2004). Freiwilligendienste zwischen Tradition und Erneuerung. In: U. Slüter, M. Schmidle \& S. Wißdorf (Hrsg.) Bürgerschaftliches Engagement. Grundlage für Freiwilligendienste (S. 15-34). Düsseldorf: Verlag Haus Altenberg.

Jax, C. (2006). Von der Pflicht zur Freiwilligkeit. Möglichkeiten und Grenzen der Kompensation des Zivildienstes durch Freiwilligendienste. Berlin: Karl Dietz Verlag.

Künzel, A. (2014). Quartiere entwickeln mit innovativen Wohn- und Pflegemodellen für ein selbstbestimmtes Wohnen. Das Netzwerk SONG: „Wer pflegt, wenn alle in Rente gehen? Zukunftskonzepte im demografischen Wandel“ (Fachtagung Wohnen „Lebensräume gestalten“, 10.10.2014). Online: http://www.wolfsburg.de/ /media/Wolfsburg/ Statistik_Daten_Fakten/Soziales/Fachtagung-Wohnen/Das-Netzwerk-SONG-Herausforderungen-Pflege-Wolfsburg-101014.ashx?la=de-DE. (zuletzt abgerufen 5.2.2016).

Liebig, R. (2009). Freiwilligendienste als außerschulische Bildungsinstitution für benachteiligte junge Menschen. Wiesbaden: VS Verlag für Sozialwissenschaften.

Lincke, H.-J. (2012). Da war doch was! Profil, Programm und Perspektiven der Freiwilligendienste aller Generationen (FDaG). Informationsdienst Altersfragen, 39(3), 11-16.

Notz, G. (2012). „Freiwilligendienste" für alle. Von der ehrenamtlichen Tätigkeit zur Prekarisierung der "freiwilligen» Arbeit. Neu-Ulm: AG-SPAK-Bücher. 
Picot, S. (2004). Freiwilliges Soziales Jahr: Eine nachhaltige Form des Engagements? In: M. Schmidle, U. Slüter \& S. Wißdorf (Hrsg.) Bürgerschaftliches Engagement. Grundlage für Freiwilligendienste (S. 59-87). Düsseldorf: Verlag Haus Altenberg.

Schmidle, M., \& Slüter, U. (2012). Einführung: Öffnung des Freiwilligen Sozialen Jahres (FSJ) für junge Menschen mit Migrationshintergrund - Weshalb sich die katholische FSJ-Trägergruppe dieser Zielgruppe öffnet. In: M. Schmidle, B. Schramkowksi \& U. Slüter (Hrsg.) Integration durch Mitmachen. FSJ für junge Menschen mit Migrationshintergrund (S. 9-16). Freiburg im Breisgau: Lambertus.

Schwesig, M. (2014). Zeit für Engagement: 50 Jahre Freiwilliges Soziales Jahr. BBE-Newsletter, 6.

Steinbach, P. (2011). Zur Geschichte der Wehrpflicht. Aus Politik und Zeitgeschichte, 61(48), 8-15.

Werkner, I.-J. (2011). Wehrpflicht und Zivildienst - Bestandteile der politischen Kultur? Aus Politik und Zeitgeschichte, 61(48), 39-45.

Wersig, T. (2015). Für mich und für andere. Das Freiwillige Soziale Jahr im politischen Leben aus der Perspektive der Freiwilligen. Marburg: Tectum.

Open Access Dieses Kapitel wird unter der Creative Commons Namensnennung 4.0 International Lizenz (http://creativecommons.org/licenses/by/4.0/deed.de) veröffentlicht, welche die Nutzung, Vervielfältigung, Bearbeitung, Verbreitung und Wiedergabe in jeglichem Medium und Format erlaubt, sofern Sie den/die ursprünglichen Autor(en) und die Quelle ordnungsgemäß nennen, einen Link zur Creative Commons Lizenz beifügen und angeben, ob Änderungen vorgenommen wurden.

Die in diesem Kapitel enthaltenen Bilder und sonstiges Drittmaterial unterliegen ebenfalls der genannten Creative Commons Lizenz, sofern sich aus der Abbildungslegende nichts anderes ergibt. Sofern das betreffende Material nicht unter der genannten Creative Commons Lizenz steht und die betreffende Handlung nicht nach gesetzlichen Vorschriften erlaubt ist, ist für die oben aufgeführten Weiterverwendungen des Materials die Einwilligung des jeweiligen Rechteinhabers einzuholen. 